\title{
Graduating from Social Protection? Editorial Introduction
}

\author{
Stephen Devereux and Rachel Sabates-Wheeler
}

Abstract Graduation programmes aim to provide a sequenced and intensive package of support to very poor people, with the objective of facilitating their movement out of extreme poverty towards resilient and sustainable livelihoods. The package usually includes regular cash transfers, productive assets, access to savings facilities, livelihood training and coaching. The success of first generation 'graduation model' programmes in Bangladesh has prompted pilot projects in several countries in Africa, Asia, Latin America and the Caribbean. This Editorial Introduction reviews alternative conceptualisations of graduation, summarises the evidence on impacts from several project evaluations presented in this IDS Bulletin, and discusses key aspects of design and implementation, including targeting, monitoring, 'asset-ness', labour market linkages and the nature of political support for graduation. The editors conclude that graduation programmes are an important and valuable contribution to development policy, but they should not displace the core social protection functions of social assistance and social insurance.

\section{What is graduation?}

To most people, graduation means leaving a school or university after completing a programme of study, once the learner has acquired a set of skills that is expected to equip them for a higher-income future livelihood. In the development discourse, however, graduation means leaving a social protection programme after reaching a wellbeing threshold, once the participant has acquired a set of resources that is expected to equip them for a higher-income future livelihood. While poverty reduction is hardly a new idea - it is, after all, the raison d'être underpinning all development policy programming for graduation is a relatively new concept.

The apparent success of 'graduation model' programmes in Bangladesh and elsewhere makes them worthy of special attention. This compilation of articles is perhaps the first that critically reviews the conceptualisation and practice of graduation programmes, across several countries and diverse contexts. ${ }^{1}$ The 14 contributions to this IDS Bulletin are organised around three questions: conceptual (what is graduation?), empirical (does graduation work?) and operational (how to do graduation?).
What is graduation? starts with this Introduction, which discusses alternative concepts of graduation and explains why this is a controversial addition to the social protection toolkit. The next article introduces the concepts of exogenous, endogenous and developmental graduation, and this is followed by an argument for intergenerational graduation.

- Does graduation work? summarises empirical evidence from evaluations of programmes in eight countries - Bangladesh, Democratic Republic of Congo, Ghana, Haiti, Kenya, Lesotho, Rwanda and Zambia. Some are national, government-run programmes but several are pilot projects financed by donor agencies and implemented by nongovernmental organisations (NGOs).

- How to do graduation? focuses on operational aspects, starting with targeting and monitoring, next cautioning that assets have characteristics that might make them unsuitable in certain contexts, then highlighting the importance of linkages to labour markets, and finally underlining the double-edged nature of political support for graduation programmes. 
Figure 1 The 'graduation model' theory of change

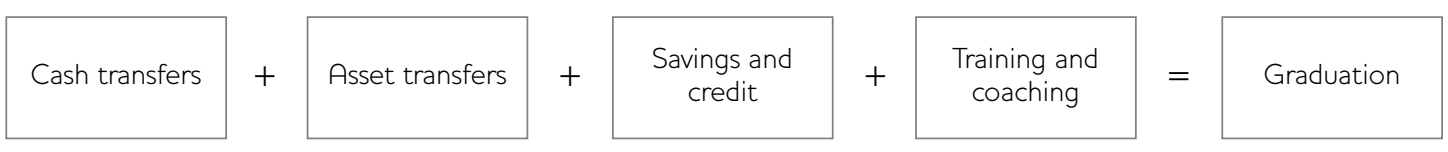

Source Authors' own.

\subsection{Graduation model programmes}

'Graduation model' programmes share a common logic and basic design features, as described in several contributions to this IDS Bulletin.

Extremely poor households are selected to receive a sequenced package of support that includes regular cash transfers for a specified period (usually 12-24 months, sometimes longer), and/or productive assets such as livestock that can generate future streams of income even after the cash transfers stop. Participants are often encouraged to save and apply for small loans, and they may also receive intensive training and coaching.

The theory of change starts from the recognition that a single intervention such as a cash transfer is unlikely to achieve a transformative impact on poor people's livelihoods, but a holistic package of support has the potential to construct a pathway out of poverty towards sustainable selfreliance (Hashemi and Umaira 2011). Cash transfers are expected to: (1) stabilise household consumption, (2) protect assets against being sold to meet basic needs, and (3) relieve liquidity constraints, allowing households to make productive investments. The promotion of savings and access to microcredit strengthens resilience to shocks and also protects the assets transferred against being sold as a 'coping strategy' following a shock. Finally, training in income-generating activities plus coaching in life-skills is sometimes described as the 'X-factor' of graduation model programmes. The intensive personal attention given to each participant aims to ensure that they make the best possible use of the resources and opportunities they receive.

The claims being made for graduation model programmes are very strong. The approach was pioneered by BRAC in Bangladesh for its Challenging the Frontiers of Poverty Reduction (CFPR) programme. According to Samson (this IDS Bulletin), the CFPR programme 'has lifted hundreds of thousands of households out of extreme poverty'. BRAC itself describes the impacts as 'astonishing' (BRAC 2013: 2). The concept was subsequently adapted by the Chars Livelihoods Programme (CLP) (see Pritchard, Kenward and Hannan, this IDS Bulletin) and the EEP/Shiree programme (see Risner and Gadhavi, this IDS Bulletin), both also in Bangladesh. With support from the Consultative Group to Assist the Poor (CGAP) and the Ford Foundation, ten pilot projects were set up to test the replicability of the model in eight countries, including Haiti (see Pain, Vautravers and Descieux, this IDS Bulletin). Impact evaluations have found that more than three-quarters of participants on these pilot projects achieved locally defined graduation criteria within three years (BRAC 2013: 5).

Concern Worldwide is also running graduation model pilot projects in Burundi and Rwanda (see Sabates and Devereux, this IDS Bulletin). National programmes that share features of the graduation model include the Vision 2020 Umurenge Programme (VUP) in Rwanda (see Gahamanyi and Kettlewell, and Sabates-Wheeler et al., this IDS Bulletin) and the Productive Safety Net Programme (PSNP) in Ethiopia (see Devereux and Ulrichs, this IDS Bulletin).

So are graduation programmes the latest 'magic bullet' for development?

\subsection{Different 'graduations'}

Michael Samson (this IDS Bulletin) proposes a typology of three distinct approaches to graduation. 'Exogenous exit' describes programmes where participants stop receiving benefits because of a change in their personal characteristics other than their poverty status, or because the programme only runs for a fixed time period. For example, South Africa's Child Support Grant delivers cash transfers until the child 'graduates' into adulthood on their eighteenth birthday. The CLP in Bangladesh and Chemin Lavi Miyo (CLM) in Haiti (see Pain, Vautravers and Descieux, this IDS Bulletin) deliver a sequenced package of support over an 18-20-month project cycle, for each cohort of 
participants. One limitation of the exogenous approach is that graduation is a 'one-way door': the CLP cannot provide additional support to households after they exit the programme, 'even while recognising that some households will not graduate; and some will slip back under the extreme poverty line' (Pritchard, Kenward and Hannan, this IDS Bulletin).

'Endogenous graduation' occurs when programmes deliver benefits until participants reach a predefined threshold on key indicators that make them no longer eligible to receive benefits. Since most graduation programmes aim to reduce extreme poverty, this typically requires an individual assessment and a re-targeting process, to determine that the household is no longer extremely poor. For example, eligibility for the VUP in Rwanda requires households to be classified in the two poorest wealth categories by their communities, and a household has graduated when their community classifies them in a higher wealth category (Sabates-Wheeler $e t$ al., this IDS Bulletin).

'Developmental graduation', according to Samson (this IDS Bulletin) 'does not necessarily involve exit from the programme'. Instead, participants receive a comprehensive range of benefits and services in addition to social protection - for example, training and microfinance - which enables them to accumulate skills, productive assets and access to livelihood opportunities, leaving them better placed to achieve sustainable self-reliance when they stop receiving programme support. Integrated graduation model programmes, according to Samson, exemplify this developmental approach.

Elsewhere, we have drawn a distinction between 'threshold' and 'sustainable' graduation

(Devereux 2010; Sabates-Wheeler and Devereux 2013). Threshold graduation could correspond to either endogenous or exogenous exit, and is triggered by participants reaching an administrative benchmark - an income level (e.g. the poverty line), a demographic characteristic (e.g. 18 years of age), or a predetermined time period (e.g. 24 months of support) - which leaves them no longer eligible to receive benefits. Sustainable graduation is closer in meaning to developmental graduation, because it incorporates a notion of resilience, meaning that graduates should not fall back into poverty soon after they exit. An example is the Government of Ethiopia's operational definition of graduation: 'A household has graduated when, in the absence of receiving PSNP transfers, it can meet its food needs for all 12 months and is able to withstand modest shocks' (FSCB 2007: 1).

But how sustainable is 'sustainable'? Roelen (this IDS Bulletin) criticises evaluations for measuring only short- to medium-term impacts: 'true sustainable graduation should be about achieving long-term improvements in livelihoods and living conditions that are maintained across generations'. Roelen argues for a shift in focus towards 'intergenerational graduation', which would require investing in children and defining success for graduation programmes in terms of breaking the intergenerational transmission of poverty. Moreover, Roelen suggests that certain design features of graduation programmes and pressures to graduate participants quickly could leave many children worse off, if too much of the household's monetary and time resources are diverted to accumulating assets and running income-generating activities. Prioritising shortterm graduation could come at the expense of long-term poverty reduction.

\subsection{Why is graduation controversial?}

Should graduation be seen as part of the social protection agenda? There is no consensus on this, partly because there is no agreed definition of social protection. One position is that social protection is essentially about safety nets and risk management ('protecting' people against shocks and risks), while another perspective is that social protection should support poor people's efforts to escape deprivation and contribute to economic growth ('promoting' people out of poverty). Graduation sits uncomfortably alongside the former conceptualisation, but is fully aligned with the latter.

At the conceptual level, graduation programmes might appear to blur the boundaries between social protection and broader development programming. Social protection has sometimes been accused of overstepping its mandate, given its origins in social welfare thinking. This is partly due to a misconception. In the case of 'transformative social protection' (Devereux and Sabates-Wheeler 2004), for instance, our argument was not that the definition of social protection should be extended to incorporate 
complementary development programmes and policies, but that many mainstream social protection instruments - such as school feeding and public works programmes - can be designed progressively to deliver on a range of impacts, including economic ones. If it is well designed and sensitively implemented, social protection can support income generation ('promotion') as well as empowerment ('transformation'), while simultaneously delivering on its core functions of social assistance ('protection') and social insurance ('prevention').

This is where the linkages become apparent. According to Samson (this IDS Bulletin), graduation is 'social protection with a developmental approach'. So why does graduation polarise opinion? Back in 2007 we co-edited an IDS Bulletin titled 'Debating Social Protection' (Devereux and Sabates-Wheeler 2007), highlighting the paradox that while social protection is generally popular, many specific aspects of social protection are deeply unpopular. Terms like 'social protection', 'employment creation', 'cash transfers' and 'redistribution' have positive connotations, but counterpart terms like 'safety nets', 'public works', 'food aid' and 'targeting' (respectively) do not.

Similarly, how graduation is framed determines how it is perceived. If it is genuinely about facilitating poverty reduction and self-reliance, who could object? But what if graduation is a politically expedient device for getting poor people off social programmes, to reduce costs and avoid creating 'dependency'? According to Kidd (2013: 3), graduation epitomises 'a neoliberal vision of social policy... The desire by some governments to "graduate" people from poor relief schemes is directly related to their perception of such schemes as "handouts"'. More generally, Reddy (2013) is sceptical about microinterventions and 'technofixes' that operate in isolation of their macro-context, and that focus on ameliorating poverty rather than enabling genuine socioeconomic transformation. To the extent that graduation programmes fit this description, they are susceptible to the criticism sometimes made against other forms of social protection: that they deliver a nominal level of assistance to the poorest individuals, without challenging - and possibly even reinforcing - the structural drivers of poverty and inequality in that society.

\section{Does graduation work?}

Assessing whether a household has graduated requires devising indicators that reflect the programme's theory of change and measuring those indicators when the programme starts (at baseline) and at least once thereafter (midline, endline and/or follow-up). To establish causality to demonstrate that any observed changes can be attributed to the programme - data on the same indicators should also be collected from a control group of individuals or households with similar characteristics to participants. Ideally, a panel of participants and non-participants (controls) would be tracked for several years, even post-exit, to assess whether graduates retain their gains and are more resilient if they face shocks. Although rigorous impact evaluations following these 'randomised controlled trial' protocols have been conducted for a few graduation programmes, the evidence base to date is limited, because graduation model programmes are relatively new and because monitoring and evaluation often stop when a programme cycle ends or when a participant graduates.

Several articles in this IDS Bulletin report on evaluation findings, though not all included a control group in their monitoring and evaluation systems, so causation can only be inferred for some cases. This section reviews the empirical evidence presented in the articles that follow this Introduction, on the main outcome indicators that graduation programmes aim to influence graduation rates, household incomes, asset ownership, savings, food security and empowerment.

\subsection{Graduation rates}

Superficially, graduation rates might seem straightforward to quantify: how many households are no longer poor when they leave the programme? In practice, this calculation is much more complex. Firstly, most graduation programmes aim to lift people out of 'extreme poverty', not poverty per se - so most graduates remain objectively poor - and extreme poverty is defined differently in different contexts.

Secondly, graduation rates are highly sensitive to the indicators that are selected and the benchmarks that define success. For example, an impressive 85 per cent of households on the Chars Livelihoods Programme (CLP-2) were assessed as having graduated after receiving 18-20 months of support. However, a sensitivity 
analysis reveals how dramatically this figure changes if the graduation threshold - which was (arbitrarily) set at achieving at least six out of ten graduation criteria - is adjusted: 65 per cent of households achieved $7 / 10$ criteria, 37 per cent achieved $8 / 10$ criteria, but only 2 per cent of 1,640 households surveyed achieved all ten criteria (Pritchard, Kenward and Hannan, this IDS Bulletin).

Also in Bangladesh, a 'development index' is used to determine whether participants have graduated when they leave BRAC's CFPR programme. Among the 2007 cohort, 74 per cent had achieved the graduation benchmarks when they exited in 2008, but this proportion actually increased to 93 per cent by 2010 - two years after programme support ended - which is a positive indicator of 'sustainable graduation' (Samson, this IDS Bulletin).

If an 'exogenous exit' approach is preferred, the calculation is much simpler: the number of graduates is simply the number of individuals or households who have received a complete cycle of project support. In Haiti's CLM, for example: 'by the end of September 2013 Fonkoze had graduated 2,364 CLM members... with a further 1,261 currently going through the programme' (Pain, Vautravers and Descieux, this IDS Bulletin). An assessment based on a poverty scorecard found that 99 per cent of participants surveyed improved their score across multiple indicators (housing, land, assets, literacy, etc.) between entering the CLM in 2007 and exiting in 2009, but four years later it was apparent that not all participants had achieved 'sustainable graduation'. In a follow-up survey in 2012, 70 per cent of these former participants had maintained or improved their poverty score from 2009, but 30 per cent registered a significant decline (Pain, Vautravers and Descieux, this IDS Bulletin).

The importance of comparing findings for graduation participants against a control group, to avoid making potentially exaggerated claims of success, is highlighted by data from Rwanda. A national household poverty survey in 2009 recorded a net national graduation rate of 17.8 per cent, meaning that almost one household in five had moved out of the two poorest community-defined wealth categories since 2006. This figure was higher in sectors where the VUP was operational, at 26.2 per cent.
If these figures were directly comparable, this would suggest that poverty reduction attributable to the VUP was not 26.2 per cent, but the 'net graduation' rate of 8.4 per cent (Asselin 2010). Similarly, since 2009, '41 per cent of the Direct Support households that received VUP support for one year (2010-11) have moved to a higher Ubudehe category by 2014 . However, in comparison, 35 per cent of Direct Supporteligible households that did not receive benefits have also moved up Ubudehe categories' (Gahamanyi and Kettlewell, this IDS Bulletin).

\subsection{Incomes}

'The ability to sustain an increase in income is a key indicator of graduation out of extreme poverty' (McIlvaine et al., this IDS Bulletin). Women on the Women for Women International's (WfWI) graduation project in Rwanda more than doubled their average daily income between joining and leaving the project. Although their incomes declined slightly thereafter, they remained at almost double their baseline level, two years after graduation.

However, the proportion of women earning more than US $\$ 1 /$ day only rose from 7 per cent to 18 per cent over this period - most remained extremely poor. In the Democratic Republic of Congo (DRC), by contrast, the proportion of women whose income exceeded US $\$ 1 /$ day increased from 5 per cent to 82 per cent between baseline and two years after graduation (McIlvaine et al., this IDS Bulletin). In Bangladesh, two years after joining the GFPR programme, former participants earned per capita incomes that were 42 per cent higher in real terms. Even after controlling for rising incomes among control group households, the attributable programme impact was a 24 per cent increase in real per capita incomes (Samson, this IDS Bulletin).

\subsection{Assets}

Productive assets are transferred as grants on many graduation programmes, very often in the form of livestock - cattle, goats, poultry (Kim and Sumberg, this IDS Bulletin). Participants also use their incremental income to acquire consumer goods and productive assets. Analysing non-land productive assets owned by CFPR programme participants in Bangladesh, Samson (this IDS Bulletin) finds that 'gross assets' increased tenfold within two years of joining the programme. Excluding assets transferred by the CFPR 
programme and also controlling for increased asset ownership by control group households, 'net assets' owned by CFPR households still increased by 43 per cent - a significant attributable programme impact.

Concern's Graduation Programme in Rwanda financed substantial acquisition of livestock in a short period of time. Participants owning smallstock (e.g. goats) increased from 7 per cent to 81 per cent after receiving cash transfers for one year, while control group households owning smallstock increased by much less, from 9 per cent to 19 per cent (Sabates and Devereux, this IDS Bulletin). Whether this accumulation will be sustained after exiting the programme requires follow-up surveys. Significantly, also in Rwanda, participants on the VUP 'only managed to build up livestock during the beneficiary period.

Thereafter... they seem to have lost the incremental livestock investment' (Gahamanyi and Kettlewell, this IDS Bulletin).

\subsection{Savings}

'Accumulating savings is an important element of the journey towards graduation' (Gahamanyi and Kettlewell, this IDS Bulletin). Encouraging a savings habit is a feature of graduation programmes, partly to protect vulnerable households against risk in the absence of insurance, and partly to build funds for investing in livelihoods. Reaching a benchmark level of savings is a graduation criterion on the CFPR, CLP and EEP/Shiree programmes in Bangladesh, and is strongly advocated or even compulsory on many other graduation programmes. On WfWI's programmes in DRG and Rwanda, the proportion of participants who had cash savings increased from 5 per cent and 18 per cent at baseline respectively, to 97 per cent in both countries two years after exiting the programme (McIlvaine et al., this IDS Bulletin). Concern Rwanda's sensitisation campaign was equally successful: among the first cohort of their Graduation Programme participants, those with savings jumped from 12 per cent to 96 per cent after one year of receiving cash transfers, while the proportion of control group households who had savings remained static at 8 per cent (Sabates and Devereux, this IDS Bulletin).

\subsection{Food security}

Cash transfers improve food security in agrarian communities in two ways: by financing food purchases and by financing investment in food production. Cash transfers are almost always used to buy food, and this was recorded for 75 per cent of VUP participants surveyed in Rwanda (Gahamanyi and Kettlewell, this IDS Bulletin). Food consumption from own-farm production increased for cash transfer recipients in Kenya and Lesotho (Daidone et al., this IDS Bulletin). Food security also relates to dietary quality and diversity. Participants on Concern's Graduation Programme in Rwanda significantly increased their consumption of meat and milk relative to control group households (Sabates and Devereux, this IDS Bulletin). On the CLP in Bangladesh, where coaching is a central component of the graduation package, 98 per cent of CLP-2 households were eating an adequate and diverse diet compared to 26 per cent of control group households, which can be explained by income effects acting in combination with behaviour change: 'the livelihoods component as well as the capacity-building and awareness-raising nutrition component' (Pritchard, Kenward and Hannan, this IDS Bulletin).

\subsection{Empowerment}

Graduation programmes often aim to promote social inclusion and empowerment. In Rwanda, Concern's Graduation Programme led to increased participation by poor participants in social ceremonies and community activities, because their self-confidence and self-esteem improved. They no longer needed to beg for help from neighbours, they could afford decent clothes to attend village meetings and they could make financial contributions when required. A statistically significant improvement between baseline and follow-up surveys was recorded on a subjective question about whether participants felt respected by their community (Sabates and Devereux, this IDS Bulletin). For similar reasons, cash transfers in Ghana and Lesotho were found 'to strengthen informal social protection systems and risk-sharing arrangements' (Daidone et al., this IDS Bulletin).

For socially disadvantaged groups, including women in many contexts, the causes of deprivation are sociocultural as much as economic. Several graduation programmes target women, even in male-headed households, in an attempt 'to foster women's empowerment to counter some perceived negative aspects of traditional male-dominated culture' (Pritchard, 
Kenward and Hannan, this IDS Bulletin). The CLP devised a 'Women's Empowerment Scorecard' to monitor trends in indicators such as the percentage of participants who can influence decisions about investments and the use of household assets, partly to assess whether income and use-value derived from assets transferred under the CLP are benefiting women or are being captured by men. When surveyed in 2014, seven times as many CLP participants (84.4 per cent) as control group women (12.5 per cent) answered that they can influence investment decisions within their households. Pritchard, Kenward and Hannan (this IDS Bulletin) attribute this improvement to women's acquisition of valuable assets and knowledge, which confers economic autonomy as well as social status within their families and communities.

WfWI's approach to graduation addresses the social as well as economic dimensions of poverty: 'WfWI aims to reduce women's overall vulnerability by increasing their financial security and enabling them to build confidence and self-esteem, understand their rights, connect with other women and become more active in their communities' (McIlvaine et al., this IDS Bulletin). In the DRC and Rwanda, this approach has succeeded in reducing both women's income poverty and their social marginalisation - they report increased confidence in social situations, for example. 'The women themselves repeatedly attribute their success firstly to their acquisition of voice and agency, and secondly to vocational and business training and the cash transfers'.

\section{How to do graduation?}

Graduation can be enabled or constrained by factors that operate at several levels, including personal characteristics of participants themselves, programme design features, local markets and the political context (SabatesWheeler and Devereux 2013). Contributions to this IDS Bulletin highlight issues in all these areas, drawing on experiences and evidence from actual programmes.

\subsection{Household-level}

As Daidone et al. (this IDS Bulletin) conclude, demographic characteristics of programme participants are a major enabler or constrainer of graduation. Programmes that deliver social welfare to labour-constrained vulnerable groups child grants, old age pensions, disability grants - target individuals with limited potential to participate in economic activities, who should not therefore be expected to graduate. This is why programmes such as the PSNP in Ethiopia and the VUP in Rwanda have sub-components specifically designed for people who are economically active (public works projects, asset packages, microfinance) and separate subcomponents for people who are economically inactive (unconditional cash transfers, or 'Direct Support'). Pressure to graduate is felt by the former category but not by the latter, who could in theory receive Direct Support indefinitely. We agree with Daidone et al.'s conclusion, that 'sustainable graduation is not a credible promise for many segments of the population, particularly households with limited labour capacity. For this group the core function of social assistance programmes should remain centred around the protection of minimum standards of living. The increasing focus on graduation should not drive resources away from households in most need of long-term protection'.

\subsection{Programme-level}

The extent to which a graduation programme can move people out of (extreme) poverty sustainably depends to a large extent on how well the programme is designed and delivered. Programme-level drivers of graduation outcomes include the amount of support provided and for how long, which people are selected into graduation programmes, how accurately progress towards graduation is monitored, and which assets are transferred to participants. Since these basic design features can all be adjusted by programme implementers, there are potentially important lessons to be learned from reviewing actual case study experiences.

\subsubsection{Value and duration of support}

The more resources are transferred to resourceconstrained households, the more likely they are to graduate - bigger transfers equal bigger impacts. Design choices that constrain graduation potential include delivering too few resources (e.g. setting a cash transfer level at the value of a basic food basket, leaving no surplus for investment), not calibrating transfers by household size (so larger households receive less per person), and failing to adjust transfers regularly to account for inflation (so their real value fluctuates seasonally and declines over time). Daidone et al. (this IDS Bulletin) note that 
the real value of a flat rate cash transfer in Kenya fell by 60 per cent in four years because of inflation, contributing just 10 per cent of per capita consumption in large households and 22 per cent in small households.

A related design feature is the duration of assistance, especially on time-bound programmes. Pritchard, Kenward and Hannan (this IDS Bulletin) hypothesise that 'better graduation rates would be achieved... if the timescale of CLP assistance was longer'. Gahamanyi and Kettlewell (this IDS Bulletin) note that 'progress towards graduation does not appear to be sustainable for many when benefits have been received only for a short time', and that re-targeting on the VUP, which started as an annual process, will be undertaken only every three years: 'This will help to maintain a longer stream of benefits for targeted beneficiaries.' In the most recent evaluation of the VUP, the largest improvements were seen among households that received continuous support over several years. 'Households that have only benefited from the programme for one year have not seen their Ubudehe status improve much.' These findings support evidence from Ethiopia and Kenya, confirming that the duration of support is critical for enabling significant and sustainable impacts, in terms of household food security and livestock accumulation (Berhane $e t$ al. 2011; Merttens et al. 2013).

\subsubsection{Targeting}

Samson (this IDS Bulletin) notes that targeting is a major challenge that complicates the achievement of developmental objectives, including graduation. Most graduation programmes require rigorous forms of targeting, aiming to reach the poorest using communitybased approaches or other mechanisms, with high direct and indirect costs that limit the coverage and scope of these interventions. Under-coverage of the poorest and most vulnerable characterises many national programmes as well as small-scale NGO projects. Also, as Daidone et al. (this IDS Bulletin) point out, programme implementers should be aware that the demographics of target groups have implications for whether graduation at scale is a realistic and achievable goal. A target group dominated by young households with working adults has greater potential to graduate than a target group dominated by older persons and the chronically ill.
Sabates-Wheeler et al. (this IDS Bulletin) raise two pertinent targeting and graduation issues: (1) the difficulty of separating the poor from the non-poor and ranking them accurately; and (2) the sensitivity of eligibility criteria, and thus graduation thresholds, to different targeting modalities. Identification of the poor/non-poor, or eligible/non-eligible, enables more accurate monitoring of changes in wellbeing, and graduation trajectories. Their analysis illustrates how difficult it is to identify the poor and the non-poor, and how inclusion of households into social programmes is determined by which coverage levels are set - which is typically a political choice. Targeting and graduation are different sides of the same coin, as the criteria for one have implications for the other. For instance, in Rwanda, eligibility for the VUP is defined by being classified in the bottom two wealth categories, while graduation (or exit) is defined by moving out of these categories. It follows that monitoring poverty eligibility criteria over time also enables monitoring of graduation trajectories. The article recommends: (1) combining participatory targeting methods with more objective but easily verifiable indicators as a way to triangulate the wealth ranking; and (2) tracking household welfare over time so that graduation is not defined merely as the opposite of programme inclusion, but also contains some indicators of long-term livelihood improvement.

\subsubsection{Monitoring}

Closely related to targeting are challenges of monitoring. As noted by Risner and Gadhavi (this IDS Bulletin), 'to operationalise a 100 per cent graduation [target] creates an imperative for programmes to focus on all of their beneficiaries, in particular the very poorest'. A requirement to focus on, and thus monitor, the majority of programme participants has significant implications for monitoring, data requirements, and by association the setting up of management and monitoring systems. If a programme is to be effective, systems must be in place to identify, track and evaluate changes to households over time. Taken seriously, this has implications for programme costs. Using the example of EEP/Shiree in Bangladesh, Risner and Gadhavi illustrate a successful example of how to build a system that can track the current status of all programme participants. They stress the importance of collecting 'real-time' and up- 
to-date census-level information that can enable adaptation of interventions for vulnerable households in a timely way. The method of realtime data collection is facilitated with a combination of smartphones and internet connectivity. While challenging and costly, the evidence emerging from EEP/Shiree shows that this kind of intensive monitoring can contribute to positive improvements in all poor people's livelihoods.

Of course, if we are to track and understand livelihood pathways, regular monitoring of 'graduation' indicators is critical. This will allow (1) accurate targeting and graduation numbers and (2) response in a timely and appropriate way to support livelihoods that may be 'failing' or facing shocks. This is a data-intensive exercise with high costs and requires high technical capacity and ability to respond. It is an aspirational agenda that appears to be working in the case of EEP/Shiree. Whether such heavy monitoring can work at scale is a question that can only be answered once tested. More 'realtime' monitoring would be welcome in any programmes attempting to support graduation.

\subsection{4 'Asset-ness'}

A defining feature of most graduation programmes is that they transfer assets to poor households. The theory of change is rarely elaborated, but essentially turns on an assumption that productive assets will generate future streams of income, so giving relevant assets to poor people will make them less poor both immediately and in the future, leading to 'asset-based graduation' (Sumberg and Lankoande 2013).

On many graduation programmes, livestock are the most popular assets transferred. In Bangladesh, 98 per cent of participants on the CLP's Asset Transfer Project chose cattle (Pritchard, Kenward and Hannan, this IDS Bulletin). But Kim and Sumberg (this IDS Bulletin) remind us that assets are highly differentiated. Livestock, for instance, come in different species, sexes, breeds and ages. Returns to assets depend on their intrinsic characteristics (their 'asset-ness'), on the characteristics (or initial conditions) of their owners, on the contexts (agro-ecological, institutional, etc.) in which they are used, and on how well they are maintained or managed.
Some assets are riskier than others. One graduation project in Pakistan introduced a breed of goats that was not well adapted to the arid local climate, and many goats starved (BRAC 2013). Another graduation pilot project in Honduras transferred chickens as a productive asset, most of which died during a poultry disease outbreak, leaving participants worse off on several indicators than before (Goldberg 2014). Such perverse outcomes could be avoided with risk assessments and adequate preparatory measures. We agree with Pain, Vautravers and Descieux (this IDS Bulletin), that "when transferring a "livelihood asset" to extremely poor people it is essential that support systems are in place to make sure they can utilise this. For instance, transferring animals as a livelihood asset, without ensuring there is a functioning veterinary service or that the beneficiaries have the capacity to manage the animals or access these services can lead to problems.'

\subsection{Market-level}

Local economies benefit directly and through multiplier effects from the injection of cash and other resources that accompany graduation programmes, but weak local economies can also limit the impacts. Most graduation programmes are implemented in poor rural communities, often characterised by thin markets and infrastructure deficits. In such contexts, the surge in demand from cash transfers might merely fuel price inflation, and the surge in supply of traded commodities produced by asset transfers and income-generating activities could overwhelm local markets. In Ethiopia, for example, 'Household Asset-Building Packages', designed to generate secondary sources of income, led to over-supply and collapse in prices for some commodities, 'because of mass production by many farmers at the same time' (Devereux et al. 2014: 21).

It follows that, since graduation requires earning independent livelihoods, 'sustainable graduation is not a credible promise in the absence of conducive market conditions' (Daidone et al., this IDS Bulletin). As a case in point, Daidone et al. found evidence that the extent to which cash transfers in rural Kenya were invested in family farms - through the purchase of fertiliser, seeds and other agricultural inputs - was higher in districts with well-developed markets for land, livestock and labour. Pain, Vautravers and 
Descieux (this IDS Bulletin) conclude that the promotion of new livelihood activities as part of graduation packages should be implemented with caution: 'a comprehensive value chain analysis needs to be undertaken beforehand, and the appropriateness of the intervention be checked'.

An emerging debate concerns the relationship between graduation programmes and labour markets. Many graduation programmes aim to increase returns to self-employment, and to alleviate dependence on unreliable and exploitative informal labour markets. Participants in rural areas tend to reallocate their labour, away from casual agricultural wage employment towards their own farms and micro-enterprises. One evaluation of BRAC's CFPR programme found that the proportion of participants who were fully self-employed rose from 30 per cent to 47 per cent, while those who depended entirely on wage labour fell from 26 per cent to 6 per cent, between joining the programme and two years after leaving it (BRAC 2013).

However, some have questioned this focus on promoting self-employment as a pathway to graduation, rather than assisting participants to find 'real jobs' with regular wages and decent working conditions. For one thing, graduation programmes often encourage participants to take loans to finance their micro-enterprises, but the microfinance literature has confirmed that for poor people, taking on debt can be highly risky. Daidone et al. (this IDS Bulletin) found that many cash transfer recipients in rural Africa are wary even of subsidised loans, for this reason: 'households remain risk averse and reluctant to take advantage of their greater access to credit'. This highlights a fundamental contradiction between two competing objectives of social protection programmes - to protect poor people against risks (the safety net function) and to encourage poor people to take risks (the economic growth function).

McCord and Slater (this IDS Bulletin) argue that the preoccupation with tackling supply-side constraints in the labour market, by attempting to turn the recipients of social transfers into microentrepreneurs, ignores the more fundamental demand-side constraints. For McCord and Slater, sustainable graduation would be better achieved by moving poor people into 'sustainable employment', which they define as 'employment which is ongoing and secure; offers adequate remuneration and working conditions; and is provided by the economy rather than external interventions (such as aid)'. Addressing the barriers to sustainable employment entails a more ambitious agenda of job creation, and improving the quality of available employment opportunities - including the provision of social security benefits.

\subsection{Political-level}

Political support for graduation programmes can be a double-edged sword. On the one hand, highlevel endorsement could be instrumental in leveraging resources from Ministries of Finance, which might otherwise be reluctant to allocate public expenditures to social programmes that are often located in weak government departments. On the other hand, political support is often accompanied by political pressure to demonstrate success and value for money, not only from politicians but also from donor agencies when these programmes are substantially financed out of development assistance budgets.

\section{As Devereux and Ulrichs (this IDS Bulletin)} argue, introducing graduation as an objective can compromise social protection programmes, if this shifts perceptions of such interventions away from welfarist social assistance for vulnerable groups, towards livelihood promotion for economically active groups. As noted above, the danger is that social protection policies will be distracted from their primary objective of guaranteeing income security for all against risks and shocks, and will be harnessed instead to the national poverty reduction agenda, which is driven by targets that require large numbers of people to graduate out of poverty and exit these programmes. One development partner in Rwanda (quoted by Devereux and Ulrichs) summed it up neatly: 'Politically, graduation makes social protection palatable.'

In Ethiopia, graduation targets have been interpreted as quotas by PSNP officials, and pressure to achieve them may have resulted in substantial premature graduation. In Rwanda, the fact that being classified as poor is associated with eligibility for programme benefits has distorted the community-based targeting process (see Sabates-Wheeler et al., this IDS Bulletin).

Stakeholders have divergent opinions on programme participants' attitudes to graduation. 
A government official in Rwanda asserted that: 'Most people do want to graduate', but a researcher in Ethiopia disagreed: 'Nobody wants to graduate' (quoted in Devereux and Ulrichs, this IDS Bulletin). One area of broad consensus concerns the need for a 'twin-track' approach, with a social safety net being put in place for poor and vulnerable people who cannot work, and graduation programmes being designed only for a subset of poor people - the new generation safety net in Ethiopia being an example of this. In some countries, though, political enthusiasm for graduation is diverting social protection programming and budgets towards groups perceived as having 'graduation potential'.

\section{Conclusion}

As poverty reduction policies and ambitions for holistic social protection systems continue to evolve, so too should our aspirations for graduation. Reflecting on the articles in this IDS Bulletin, it is clear that the people who design graduation model programmes understand that poverty is too complex to be solved with a single instrument such as cash transfers. Graduation programmes strive to enhance livelihoods and strengthen resilience by providing integrated packages of support - cash, productive assets, access to financial services, training and coaching - in a holistic effort to address the wide spectrum of resource deficits that keep people trapped in poverty and vulnerability.

This does not mean that the perfect package has yet been designed. We do not yet understand the optimal combinations of support for people in different contexts, or the best ways to build

\section{Note}

1 The contributions to this IDS Bulletin draw on presentations made at the international conference 'Graduation and Social Protection', hosted by the Government of Rwanda in Kigali on 6-8 May 2014. The conference received financial support from Irish Aid, UNICEF and the UK Department for International Development (DFID). The

\section{References}

Asselin, L. (2010) VUP Targeting and Poverty Surveys 2009: Final Report, Kigali: Government of Rwanda

Berhane, G.; Hoddinott, J.; Kumar, N.; Tafesse, A.; Diressie, M.; Yohannes, Y.; Sabates-Wheeler, R.; Handino, M.; Lind, J.; Tefera, M. and Simma, F. linkages and maximise synergies across complementary sectoral interventions. The assumption of a smooth linear pathway out of poverty might also seem naïve, as it overlooks the unpredictable and often erratic nature of poor people's livelihood trajectories.

Graduation programmes focus on moving people out of extreme poverty as quickly as possible, making little effort to challenge the structural conditions that are the fundamental drivers of poverty and vulnerability. This is partly because they are expensive and require multi-annual spending commitments, but governments and donors are under increasing pressure to show results fast. Realistic expectations and time frames for graduation are, therefore, often sacrificed to the imperatives of speed and valuefor-money calculations. For these reasons, most programmes still fail to bolster livelihoods adequately for the long run - that is, for sustainable, intergenerational graduation rather than simply for programme exit.

Nonetheless, the achievements of graduation programmes are impressive. They might not be a 'magic bullet' and they should not be seen as a substitute for the core social protection functions of social assistance and social insurance, but they offer a fresh approach to tackling poverty and vulnerability. At a time when social protection is moving towards integrated systems and strengthening cross-sectoral linkages with complementary social and economic policies, graduation programmes add real value to efforts to build more secure, sustainable and resilient livelihoods.

conference was one activity of a Centre for Social Protection (CSP) workstream, under a partnership agreement between Irish Aid and the UK Institute of Development Studies (IDS). For conference presentations and other outputs on the theme of graduation and social protection, see www.ids.ac.uk/graduationconference.

(2011) Evaluation of Ethiopia's Food Security

Programme: Documenting Progress in the Implementation of the Productive Safety Nets Programme and Household Assets Building Programme, Report to the PSNP Donor Coordination Team, Addis Ababa: World Bank 
BRAC (2013) An End in Sight for Ultra-poverty: Scaling up BRAC's Graduation Model for the Poorest, Briefing Note 1: Ending Extreme Poverty, Dhaka: BRAC

Devereux, S. (2010) Dependency and Graduation, Frontiers of Social Protection Brief 5, Johannesburg: Regional Hunger and Vulnerability Programme (RHVP)

Devereux, S. and Sabates-Wheeler, R. (eds) (2007) 'Debating Social Protection', IDS Bulletin 38.3, Brighton: IDS

Devereux, S. and Sabates-Wheeler, R. (2004) Transformative Social Protection, IDS Working Paper 232, Brighton: IDS

Devereux, S.; Sabates-Wheeler, R.; Mulugeta, T.; Sabates, R. and Feyera, S. (2014) Graduation from the Food Security Programme in Ethiopia, FAC Working Paper 080, Brighton: Future Agricultures Consortium

FSCB (Food Security Coordination Bureau) (2007) Graduation Guidance Note, Addis Ababa: Ministry of Agriculture and Rural Development, Government of Ethiopia Goldberg, N. (2014) 'Impact of the Graduation Project', presentation at the international conference Graduation and Social Protection, Kigali, Rwanda, 6-8 May
Hashemi, S. and Umaira, W. (2011) New Pathways for the Poorest: The Graduation Model from BRAC, CSP Research Report 10, Brighton: Centre for Social Protection, IDS

Kidd, S. (2013) The Misuse of the Term 'Graduation' in Social Policy, Pathways Perspectives 14, Banbury: Development Pathways

Merttens, F.; Hurrell, A.; Marzi, M.; Attah, R.; Farhat, M.; Kardan, A. and MacAuslan, I. (2013) Kenya Hunger Safety Net Programme Monitoring and Evaluation Component Impact Evaluation, Final Report: 2009 to 2012, Oxford: Oxford Policy Management

Reddy, S. (2013) 'Randomise This! On Poor Economics', Review of Agrarian Studies 2.2, www.ras.org.in/randomise_this_on_poor economics (accessed 11 February 2015)

Sabates-Wheeler, R. and Devereux, S. (2013)

'Sustainable Graduation from Social Protection Programmes', Development and Change 44.4: 911-38

Sumberg, J. and Lankoande, G. (2013) 'Heiferin-trust, Social Protection and Graduation: Conceptual Issues and Empirical Questions', Development Policy Review 31.3: 255-71 